\title{
Basal Cerebral Metabolism May Modulate the Cognitive Effects of $A \beta$ in Mild Cognitive Impairment: An Example of Brain Reserve
}

\author{
Ann D. Cohen, ${ }^{1}$ Julie C. Price, ${ }^{2}$ Lisa A. Weissfeld, ${ }^{3}$ Jeffrey James, ${ }^{2}$ Bedda L. Rosario, ${ }^{2}$ Wenzhu Bi, ${ }^{3}$ Robert D. Nebes, ${ }^{1}$ \\ Judith A. Saxton, ${ }^{4}$ Beth E. Snitz, ${ }^{4}$ Howard A. Aizenstein, ${ }^{1}$ David A. Wolk ${ }^{4,5}$ Steven T. DeKosky, ${ }^{1,4,6}$ Chester A. Mathis, ${ }^{2}$ \\ and William E. Klunk ${ }^{1,4}$ \\ Departments of ${ }^{1}$ Psychiatry, ${ }^{2}$ Radiology, ${ }^{3}$ Biostatistics, and ${ }^{4}$ Neurology, University of Pittsburgh School of Medicine, Pittsburgh, Pennsylvania 15261, \\ ${ }^{5}$ Department of Neurology, University of Pennsylvania School of Medicine, Philadelphia, Pennsylvania 19104, and ${ }^{6}$ Department of Neurology, \\ University of Virginia School of Medicine, Charlottesville, Virginia 22908
}

\begin{abstract}
Inverse correlations between amyloid- $\beta(\mathrm{A} \beta)$ load measured by Pittsburgh Compound-B (PiB) positron emission tomography (PET) and cerebral metabolism using $\left[{ }^{18} \mathrm{~F}\right]$ fluoro-2-deoxy-D-glucose (FDG) in Alzheimer's disease (AD) patients, suggest local A $\beta$-induced metabolic insults. However, this relationship has not been well studied in mild cognitive impairment (MCI) or amyloid-positive controls. Here, we explored associations of $\mathrm{A} \beta$ deposition with metabolism via both region-of-interest-based and voxel-based analyses in amyloidpositive control subjects and patients with $\mathrm{MCI}$ or AD. Metabolism in parietal and precuneus cortices of AD patients was negatively correlated with $\mathrm{PiB}$ retention locally, and more distantly with PiB retention in frontal cortex. In amyloid-positive controls, no clear patterns in correlations were observed. In MCI patients, there were essentially no significant, negative correlations, but there were frequent significant positive correlations between metabolism and PiB retention. Metabolism in anterior cingulate showed positive correlations with $\mathrm{PiB}$ in most brain areas in $\mathrm{MCI}$, and metabolism and PiB retention were positively correlated locally in precuneus/ parietal cortex. However, there was no significant increase in metabolism in MCI compared to age-matched controls, negating the possibility that $\mathrm{A} \beta$ deposition directly caused reactive hypermetabolism. This suggests that, in $\mathrm{MCI}$, higher basal metabolism could either be exacerbating $\mathrm{A} \beta$ deposition or increasing the level of $\mathrm{A} \beta$ necessary for cognitive impairment sufficient for the clinical diagnosis of $\mathrm{AD}$. Only after extensive $\mathrm{A} \beta$ deposition has been present for longer periods of time does $\mathrm{A} \beta$ become the driving force for decreased metabolism in clinical $\mathrm{AD}$ and, only in more vulnerable brain regions such as parietal and precuneus cortices.
\end{abstract}

\section{Introduction}

Amyloid- $\beta(\mathrm{A} \beta)$ has been associated with the pathogenesis of Alzheimer's disease (AD). However, there is postmortem evidence for $\mathrm{A} \beta$ deposition in cognitively normal elderly (Price and Morris, 1999) and mild cognitive impairment (MCI) (Petersen et al., 2006). Some have reported postmortem A $\beta$ is present in 25 $40 \%$ of cognitively unimpaired elderly (Wolf et al., 1999; Bennett et al., 2006) and, using Pittsburgh Compound-B (PiB), several have reported $\sim 25 \%$ of clinically unimpaired, elderly controls

\footnotetext{
Received July 29, 2009; accepted 0ct. 5, 2009.

This work was supported by National Institutes of Health Grants R01 AG018402, P50 AG005133, K02 AG001039, R01 MH070729, K01 MH001976, R37 AG025516, P01 AG025204, and K02 AG027998; Alzheimer's Association Grant TLL-01-3381; and U.S. Department of Energy Grant DE-FD02-03 ER63590.

GE Healthcare holds a license agreement with the University of Pittsburgh based on the technology described in this manuscript. W.E.K. and C.A.M. are coinventors of PiB and, as such, have a financial interest in this license agreement. GE Healthcare provided no grant support for this study and had no role in the design or interpretation of results or preparation of this manuscript. All other authors have no conflicts of interest with this work and had full access to all of the data in the study and take responsibility for the integrity of the data and the accuracy of the data analysis.

Correspondence should be addressed to Dr. William E. Klunk, Western Psychiatric Institute and Clinic, Room 1422 TDH, 3811 0’Hara Street, Pittsburgh, PA 15213-2593. E-mail: klunkwe@upmc.edu. D0I:10.1523/JNEUROSCI.3669-09.2009

Copyright $\odot 2009$ Society for Neuroscience $\quad$ 0270-6474/09/2914770-09\$15.00/0
}

display increased PiB (Mintun et al., 2006; Aizenstein et al., 2008). These findings are consistent with poor correlations between postmortem $\mathrm{A} \beta$ and cognitive decline in $\mathrm{AD}$ (Prohovnik et al., 2006). If $A \beta$ accumulation eventually causes the cognitive deficits of $\mathrm{AD}$, the lack of direct correlations requires one or more mediators between $\mathrm{A} \beta$ and cognitive decline. These mediators could be $A \beta$-facilitatory, such as tau (Bennett et al., 2004), oligomeric forms of $\mathrm{A} \beta$ (Shankar et al., 2008), or vascular pathology (Schneider et al., 2007). Conversely, these mediators could be $\mathrm{A} \beta$-suppressive (minimizing cognitive-impairments), such as factors responsible for cognitive or brain reserve (Stern et al., 2003). Due to difficulties with postmortem analysis, it is important to use in vivo biomarkers to measure $\mathrm{A} \beta$ in close temporal proximity to cognitive testing to distinguish these possibilities.

Lowered cerebral metabolism, using $\left[{ }^{18} \mathrm{~F}\right]$ fluoro-2-deoxy-Dglucose (FDG), shows a pattern of temporoparietal $>$ frontal hypometabolism in AD (Friedland et al., 1983; Foster et al., 2007; Jagust et al., 2007). Similar hypometabolism was reported in carriers of the apolipoprotein-E $\varepsilon 4$ allele, an $\mathrm{AD}$ risk factor (Reiman et al., 1996; Small et al., 2000). Inverse correlations were observed between postmortem $\mathrm{A} \beta$ deposition compared to in vivo metabolism using FDG, $8 \mathrm{~h}$ before the death of a single $\mathrm{AD}$ patient 
(Mega et al., 1999). Similarly, in vivo $\mathrm{PiB}$ has been reported to show negative correlations with metabolism in parietal cortex in AD (Klunk et al., 2004; Engler et al., 2006), but this is not always observed (Kadir et al., 2008). In contrast, there has been little exploration of correlations between $\mathrm{PiB}$ and cerebral metabolism in MCI (Forsberg et al., 2008) and, to our knowledge, no explorations in clinically unimpaired elderly subjects. Here, we explored the associations of $\mathrm{A} \beta$ with metabolism across the cognitive spectrum of $\mathrm{AD}$. We used a region-of-interest (ROI) and correlation matrix approach, and then used these data to inform selected voxel-based analyses.

\section{Materials and Methods}

Human subjects. Amyloid-positivity was defined as previously reported (Aizenstein et al., 2008)). Equal numbers $(n=14)$ were chosen for each group so that the magnitude of the correlation coefficients and the level of significance could be directly compared across groups, particularly in the voxel-based statistical parametric mapping (SPM) analyses described below. The number of available amyloid-positive MCI cases $(n=14)$ limited numbers included in the other two groups. Amyloid-negative control and MCI cases were not included in the correlations to avoid misleading correlations caused by clusters of subjects in the amyloidnegative group leading to a non-homogeneous population. The first 14 amyloid-positive MCI patients [from 24 total (58\%); 11 male, 3 female; mean age: $73.1 \pm 6.5$ years, Mini Mental State Exam (MMSE): $27 \pm 3$ ], the first 14 consecutive amyloid-positive normal control subjects [from 49 total (28\%); 6 male, 8 female; mean age: $70.8 \pm 7.6$ years, MMSE: $29 \pm$ 1 ], and the first 14 consecutive amyloid-positive $\mathrm{AD}$ patients [from 14 total (100\%); 11 male, 3 female: mean age: $72.1 \pm 9.7$ years, MMSE: $23 \pm$ 3 ] were included in the correlation component of this study. In addition to these subjects used for the primary analyses, an additional 24 agematched, cognitively normal, amyloid-negative subjects (10 male, 14 female; mean age: $72.6 \pm 5.3$ years, MMSE: $29 \pm 1$ ) were used as a comparative group for cerebral metabolic measures. All subjects were evaluated with the standard neurological, psychiatric, and neuropsychological examinations used at the University of Pittsburgh Alzheimer Disease Research Center (ADRC) as described previously and briefly below (Lopez et al., 2000; Price et al., 2005; Aizenstein et al., 2008). All subjects and their caregivers (when appropriate) provided informed consent for both the ADRC clinical examination and the positron emission tomography (PET) imaging protocol. This study was approved by the Human Use Subcommittee of the Radioactive Drug Research Committees and the Institutional Review Board of the University of Pittsburgh.

Subjects unique to this study. The subjects reported in this study represent a combination of subjects reported in earlier analyses of different aspects of $\mathrm{A} \beta$ deposition as well subjects studied since those analyses (Lopresti et al., 2005; Price et al., 2005; Ziolko et al., 2006; Klunk et al., 2007; Aizenstein et al., 2008; Raji et al., 2008). The subjects that are unique to this study include one control subject, seven MCI subjects, and four $\mathrm{AD}$ subjects.

Neuropsychological evaluation. The neuropsychological test battery was designed to assess those areas of cognition known to be impaired in AD and also to be sensitive to MCI (Petersen, 2004; Gauthier et al., 2006) and included tests of attention, memory, visuoconstructive/spatial ability, language, and executive functioning. The test batteries included the MMSE (Folstein et al., 1975), Clinical Dementia Rating Scale (CDR) (Morris, 1993), the Consortium to Establish a Registry for Alzheimer's Disease, Word List Learning, Delayed Recall Test (Welsh et al., 1994), the Wechsler Adult Intelligence Scale III Digit Span forward and backward (Wechsler, 1997), Trail Making Parts A and B (Reitan, 1958), letter fluency (FAS total) (Benton, 1968), category fluency (animals) (Borkowski et al., 1967), Boston Naming Test (Saxton 30-item version) (Saxton et al., 2000), and Modified Rey-Osterrieth Figure copy (maximum of 24) (Becker et al., 1987).

PET studies: tracer and acquisition. High specific activity $\left[{ }^{11} \mathrm{C}\right] \mathrm{PiB}$ was produced as previously described (Wilson et al., 2004; Price et al., 2005). FDG was synthesized by a standard method (Hamacher et al., 1986). The PiB PET data were acquired as described by Lopresti et al. (2005). Briefly, before the PET imaging sessions, a spoiled gradient recalled (SPGR) magnetic resonance (MR) scan was obtained for each subject for MRPET image coregistration and anatomical ROI definition as previously described (Lopresti et al., 2005; Price et al., 2005). The MR-based partial volume correction corresponded to a two-component approach that corrected the PET PiB and FDG measures for the dilutional effect of expanded CSF spaces accompanying normal aging or disease-related cerebral atrophy (Meltzer et al., 1999). Basically, this approach generated \%brain and \%CSF values for each ROI and then the PiB-distribution volume ratio (DVR) or FDG-SUV tissue ratio (SUVR) values were corrected by dividing by the \%brain value for that ROI. Right and left ROIs were separately hand-drawn on the coregistered MR image and included the following: frontal cortex (ventral and dorsal), anterior cingulate cortex (subgenual and pregenual), mesial temporal cortex (includes hippocampus and amygdala), precuneus/posterior cingulate cortex (ventral, middle and dorsal thirds), parietal cortex, lateral temporal cortex, occipital cortex (calcarine and pole), and cerebellum (Fig. 1; supplemental Fig. 1, available at www.jneurosci.org as supplemental material). PET imaging was conducted using a Siemens/CTI ECAT HR + (threedimensional mode, $15.2 \mathrm{~cm}$ field-of-view, 63 planes, reconstructed image resolution $\sim 6 \mathrm{~mm}$ ). The subject's head was immobilized to minimize head motion during the scan. PiB was injected intravenously (12-15 $\mathrm{mCi}$, over $20 \mathrm{~s}$, specific activity $\sim 1-2 \mathrm{Ci} / \mu \mathrm{mol}$ ) and dynamic PET scanning was performed over 90 min (34 time frames). FDG was injected intravenously $(6-7.5 \mathrm{mCi}) \sim 2 \mathrm{~h}$ after the start of the PiB scan. The FDG-PET scan was acquired over 25 min (five 5 min frames) after a 35 min uptake period as the subjects rested quietly in a dimly lit room with their eyes open. Analysis of the PiB-PET data used a Logan graphical analysis of the 90 min dynamic PiB-PET scan with the cerebellum as reference (CER90) to produce a DVR (where DVR $=\mathrm{V}_{\mathrm{T}} / \mathrm{V}_{\mathrm{ND}}$ ) as described in detail by Lopresti et al. (2005). The FDG-PET data were analyzed via summed images in a manner consistent with established methods (Minoshima et al., 1995; Herholz et al., 2002; Ziolko et al., 2006). The FDG data were summed over 40-60 min postinjection (4 frames) and a standardized uptake value (SUV) was obtained by normalizing tissue radioactivity concentration $(\mu \mathrm{Ci} / \mathrm{ml})$ by injected dose $(\mathrm{mCi})$ and body mass (in units of $\mathrm{ml}$, making the approximation that $1 \mathrm{~g}$ equals $1 \mathrm{ml}$ ). SUVR value was generated for each ROI by normalization to the cerebellum.

Statistical analysis. Corrections for multiple comparisons used false discovery rate (FDR) control at the "customary" levels of $q=0.01,0.05$ or 0.1 (i.e., $1 \%, 5 \%$ or $10 \%$ false positives) (Cheng et al., 2004). Multiple ROI-based analyses in the MCI group and many voxels in the SPM analyses survived FDR control at $q=0.1$. Several of the ROI-based analyses in the MCI subjects (but no voxel-based analyses) survived FDR control at $q=0.05$. No correlations survived FDR control at $q=0.01$. While FDR control at $q=0.1$ is on the liberal end of correction for multiple comparisons, we are not focusing conclusions on the results of any single brain voxel or cell in the correlation matrix, but rather are looking for broad patterns across many cells or voxels to arrive at general conclusions. Group comparisons of PiB-DVR and FDG-SUVR were performed using a Student's $t$ test.

Voxel-based analysis. High-resolution, skull-cropped, 1.5T SPGR images were reoriented along the AC-PC line and the medial longitudinal fissure. These images were normalized to the ICBM 152 template (Montreal Neurological Institute) using tissue priors and the unified segmentation technique (Ashburner and Friston, 2005) of the SPM5 software package (http://www.fil.ion.ucl.ac.uk/spm/software/ spm5/). PiB-DVR and FDG-SUVR parametric images were prepared by applying a positive mask, coregistering to the corresponding MR image, and transforming into template space using the factors created during segmentation. Voxelwise statistical correlations also were performed with SPM5. Voxels with DVR values $<0.75$ DVR were considered to have an unacceptable contribution from noise and were therefore excluded from these analyses. The resultant maximum intensity projections are shown with a FDR threshold of 0.1 (Fig. $2 A, D$ ), or an uncorrected $p$ value threshold of 0.05 (Fig. $2 B, C$ ), and a voxel extent threshold of 30 . Bilateral precuneus or bilateral anterior cingulate ROIs were used as the comparator regions. For these voxel-based analyses, the precuneus ROI values were the average across the ventral, middle and 
dorsal thirds of both the left and right precuneus. The anterior cingulate ROI values were the average across subgenual and pregenual anterior cingulate of both left and right anterior cingulate.

Correlation matrices. Matrices for the control, $\mathrm{MCI}$, and $\mathrm{AD}$ groups were organized in an approximately anterior to posterior manner (Fig. 1) with the PiB-DVR of each ROI organized in columns and FDG-SUVR of each ROI organized in rows. Pearson's correlation coefficients and the corresponding $p$ values were then determined for PiB-DVR in each ROI compared to FDG-SUVR in that same ROI as well as every other ROI. Correlation coefficients with $p$ values significant after FDR control at $q=0.05$ or $q=0.1$ were then color coded using cool colors for negative correlations (blue: FDR $<0.05$; cyan: FDR $<0.1$ ) and warm colors for positive correlations (red: FDR $<0.05$; orange: FDR $<0.1)$ Correlations with uncorrected $p<0.05$ that did not survive FDR control, were indicated in white (negative correlations) or yellow (positive correlations).

\section{Results}

$\mathrm{PiB}$ retention and metabolism were correlated in 24 brain areas [right and left sided frontal cortex (ventral and dorsal), anterior cingulate (subgenual and pregenual), mesial temporal cortex (includes hippocampus and amygdala), precuneus (ventral, middle, and dorsal thirds), parietal, lateral temporal, and occipital cortex (calcarine and pole)]. Image-based definitions of these ROIs can be found in supplemental Figure 1, available at www. jneurosci.org as supplemental material. All 576 possible correlations were calculated in controls, MCI, and AD patients ( $n=14$ in each group; all were amyloid positive). In Figure 1 , the negative correlations (matrices $I-I V a, c, e$ ) and positive correlations (matrices $I-I V b, d, f$ ) are shown in separate matrices so they do not obscure each other. In addition, we have further grouped the correlations matrices into left-PiB:left-FDG (matrices $I a-f$ ), right-PiB:right-FDG (matrices $I I a-f$ ), left-PiB:rightFDG (matrices $I I I a-f$ ) and right-PiB:left-FDG (matrices $I V a-f$ ). This allows clearer identification of local and distant correlations. Thus, Figure 1 shows eight separate correlation matrices for each of the three diagnostic groups. To show the regional patterns evident in the correlation matrices, brain areas are arranged, in an approximately anterior-to-posterior order from left-to-right and from top-to-bottom with $\mathrm{PiB}$ retention in columns and metabolism in rows. Odd numbered rows and columns are used for left-sided regions and even numbered rows and columns are used for right-sided regions. This arrangement keeps local correlations on or near the diagonal and more distant correlations fall off the diagonal. Significance levels in Figure 1 are color coded, similar in concept to the pseudo-color images of a PET scan. All positive correlations in Figure 1 are shown in warm colors (yelloworange-red with red representing the most significant positive correlations, FDR <0.05) and all negative correlations are shown in cool colors (white-cyan-blue with blue representing the most significant negative correlations, FDR $<0.05$ ). The actual Pearson's $r$ values are shown in supplemental Tables $1-3$, available at www.jneurosci.org as supplemental material.
II

III

IV
R-PiB vs. L-FDG

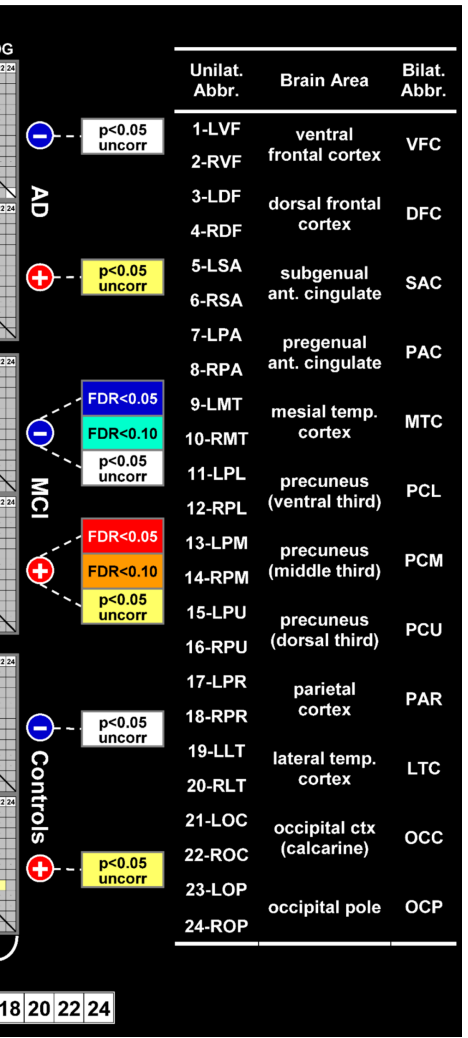

PiB in Columns

(1)

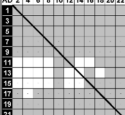

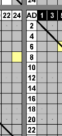

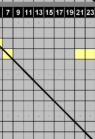

(2)
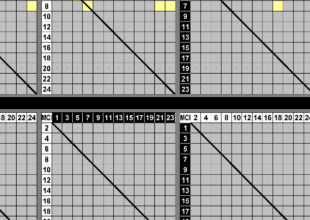

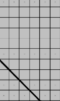

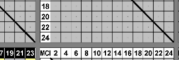

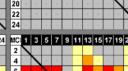

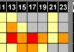

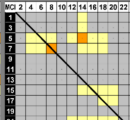

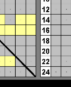
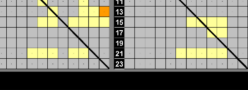

(2022)
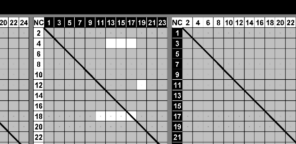

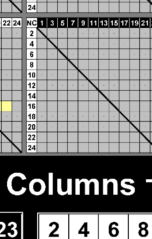

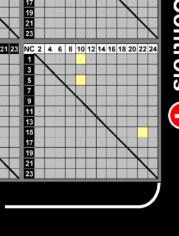

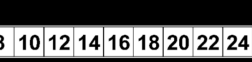

Figure 1. Correlation matrices for controls, MCl, and $A D$. Positive correlations are shown in red and negative correlations are left-sided ROls and even/black numbers for right-sided ROls. Additional details about the organization of the matrices are described in the methods and results sections.

All PiB-DVR and FDG-SUVR results discussed below are atrophy corrected because the goal was to compare $A \beta$ deposition per unit of tissue to metabolism per unit of tissue in isolation from the effects of atrophy. Parallel analyses done without atrophy correction gave a qualitatively similar outcome that resulted in the same general conclusions, although the correlations were somewhat less robust.

\section{Association of $\mathrm{A} \boldsymbol{\beta}$ deposition and glucose metabolism in $\mathrm{AD}$ patients \\ ROI-based analyses}

In the description of ROI-based correlations below, only general patterns will be discussed in detail. Isolated correlations consisting of one or two cells with weaker correlations can be seen in Figure 1, but will not be discussed here.

Negative correlations (Fig. 1, matrices Ia-IVa). Similar to previously reported results, negative correlations (uncorrected $p<$ 0.05 ) were observed between $\mathrm{PiB}$ retention and metabolism in AD patients (Klunk et al., 2004; Engler et al., 2006). The most extensive local negative correlations of $\mathrm{PiB}$ retention and metabolism were in the left parietal and precuneus cortex (matrix Ia: rows/columns 11-17). Additionally, metabolism in the left precuneus showed multiple significant correlations with $\mathrm{PiB}$ retention in the right frontal areas (matrix IVa: columns 2-8 and rows 11-17).

Positive correlations (Fig. 1, matrices Ib-IVb). Compared to the many negative correlations observed in the $\mathrm{AD}$ patients, there were relatively few positive correlations $(\sim 1 / 3$ the number of negative correlations). The strongest positive correlations were 

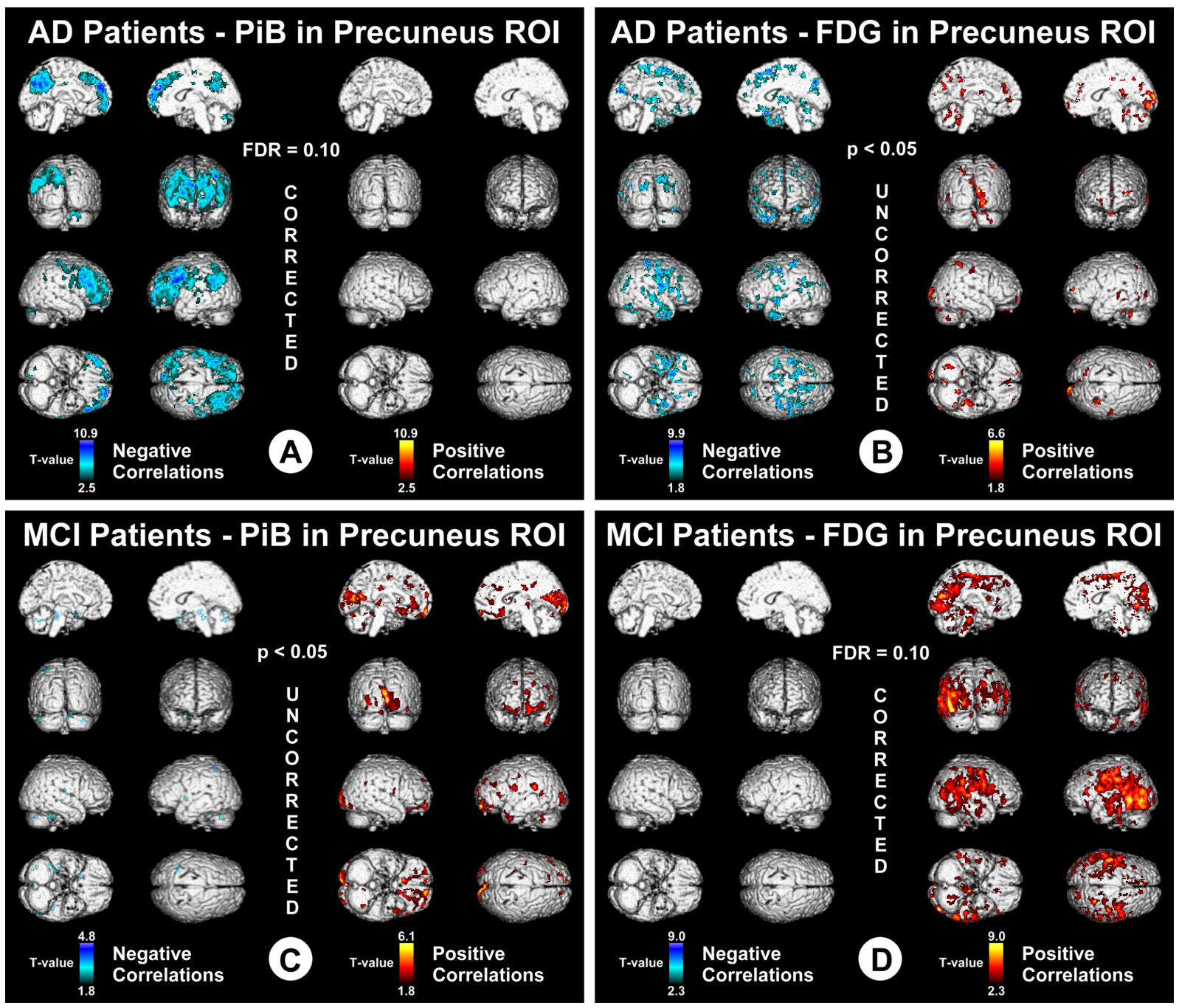

Figure 2. Voxel-based correlations in AD and MCI. $A$, T values associated with negative correlations (blue) and positive correlations (red) in AD, between PiB retention in the bilateral/combined precuneus ROI and voxel-based measures of metabolism throughout the brain. Data are thresholded with FDR control at $q=0.1 . B, T$ values associated with negative correlations (blue) and positive correlations (red) in AD, between FDG metabolism in the bilateral/combined precuneus ROl and voxel-based measures of PiB retention throughout the brain. Data are thresholded at an uncorrected $p<0.05$. C, T values associated with negative correlations (blue) and positive correlations (red) in $\mathrm{MCl}$, between PiB retention in the bilateral/combined precuneus $\mathrm{ROI}$ and voxel-based measures of metabolism throughout the brain. Data are thresholded at an uncorrected $p<0.05 . D$, $T$ values associated with negative correlations (blue) and positive correlations (red) in MCl, between FDG metabolism in the bilateral/combined precuneus ROI and voxel-based measures of PiB retention throughout the brain. Data are thresholded with FDR control at $q=0.1$.

observed between metabolism in the anterior cingulate and $\mathrm{PiB}$ retention in anterior cingulate and occipital cortex (matrices $I b$ to $I V b$ : rows 5-8).

Voxel-based analyses in $A D$

The results of the ROI-based analysis discussed above were used to generate hypotheses to guide a limited set of voxel-based analyses. Because PiB retention in the precuneus region showed the strongest correlations with metabolism, we correlated the PiB retention values in the precuneus with metabolism in all brain voxels. Figure $2 \mathrm{~A}$ shows extensive local negative correlations between $\mathrm{PiB}$ retention in precuneus (bilateral average) and metabolism in the precuneus and parietal regions, similar to the observations reported above in the ROI-based analysis. In addition, this voxel-based analysis showed distant negative correlations between $\mathrm{PiB}$ retention in the precuneus and metabolism in frontal areas of the brain (Fig. $2 A$ ) that were much less evident in the ROI-based analysis. The left-sided predominance of the local precuneus and parietal correlations observed in the ROI-based analyses (Fig. 1, matrix Ia vs matrix IIa) also are evident in Figure $2 A$. As in the ROI-based analysis, there were very few positive correlations between $\mathrm{PiB}$ retention in the precuneus $\mathrm{ROI}$ and voxel-based measures of metabolism (Fig. $2 A$ ). Interestingly, correlating the FDG-SUVR in the precuneus with PiB-DVR across all voxels (Fig. $2 \mathrm{~B}$ ) did not result in nearly as many robust correlations (i.e., the correlations did not survive FDR control at $q=0.1)$ as when PiB ROI data were correlated with FDG voxel data (Fig. 2A).

\section{Association of $\mathrm{A} \boldsymbol{\beta}$ deposition and glucose metabolism in MCI patients}

ROI-based analyses

Negative correlations (Fig. 1, matrices Ic-IVc). A notable finding in the correlations performed in the MCI patients was the complete lack of significant negative correlations between PiB retention and metabolism. None of the 576 regional correlations 
between PiB retention and metabolism had a Pearson's r value of less than -0.25 (uncorrected $p=0.39$ ).

Positive correlations (Fig. 1, matrices Id-IVd). Another highly notable finding in the MCI group was the large number of positive correlations between $\mathrm{PiB}$ retention and metabolism that were observed in 28\% (159 of 576) of the brain areas (Fig. 1, matrices $I d$ to $I V d)$. The most significant and extensive of the local positive correlations were found in the frontal areas, including bilateral anterior cingulate (matrices Id,IId: rows/columns 5-8) and left frontal cortex (matrix Id: rows/columns 1 and 3). In addition to showing strong local correlations, anterior cingulate metabolism was positively correlated with $\mathrm{PiB}$ retention in a large majority of more distant brain regions bilaterally (matrices $I d$ to $I V d$ : rows 5-8). A clear pattern of left-predominance emerged. Metabolism in left frontal cortex being significantly correlated with PiB retention in almost all left hemispheric ROIs (matrix Id: rows 1 and 3), but only a single correlation was observed with right frontal metabolism (matrix IId: rows 2 and 4). Local positive correlations were also seen in posterior areas, including the precuneus/parietal regions bilaterally (matrices Id,IId: rows/columns 11-18). Metabolism in the precuneus also was significantly correlated with $\mathrm{PiB}$ retention in distant brain regions including the lateral temporal and occipital regions (matrices $I d$ to $I V d$ : rows 11-16 and columns 19-24). Metabolism in the occipital ROI showed several distant correlations as well, most notably with $\mathrm{PiB}$ retention in precuneus, parietal and lateral temporal cortex (matrices $I d$ to $I V d$ : row 21 and columns 11-20).

Voxel-based analyses in MCI

As seen above for the analyses in AD patients, the voxel-based analyses in the MCI group corresponded well with the ROI-based analyses. The most striking findings were observed when metabolism in the precuneus ROI (Fig. 2D) was correlated with PiB retention throughout the brain. There were essentially no negative correlations between metabolism in the precuneus and $\mathrm{PiB}$ retention in any neocortical voxel (Fig. $2 \mathrm{D}$ ). As in the ROI-based analysis, metabolism in the precuneus showed extensive local positive correlations to $\mathrm{PiB}$ retention in the precuneus as well as more distant positive correlations throughout the posterior neocortex (parietal and occipital cortex), but almost no distant positive correlations with $\mathrm{PiB}$ retention in frontal areas (Fig. 2C). Reminiscent of (but opposite to) the phenomenon in AD patients, correlations were much less robust when $\mathrm{PiB}$ retention in the precuneus ROI was regressed against metabolism in all voxels (Fig. 2D).

\section{Association of $\mathrm{A} \boldsymbol{\beta}$ deposition and glucose metabolism in control subjects ROI-based analyses (Fig. 1, matrices I-IVe,f) \\ Compared to either AD or MCI patients, there were relatively few significant correlations in control subjects and there was no large predilection for either positive or negative correlations. Despite the paucity of significant correlations, the pattern was not com- pletely random as most correlations included metabolism in the dorsal-frontal cortex, parietal cortex, and precuneus.}

Voxel-based analyses in controls

As predicted by the ROI-based analyses, essentially no significant correlations were observed between $\mathrm{PiB}$ retention or metabolism in the precuneus ROI and the complementary voxel-based data (data not shown).
Comparison of $\mathrm{A} \boldsymbol{\beta}$ deposition and glucose metabolism in amyloid-negative control subjects to the amyloid-positive groups

We compared $A \beta$ deposition and metabolism in amyloidnegative controls to that in amyloid-positive controls, amyloidpositive MCI and AD patients (Fig. 3). Since metabolism is reduced with age (Herholz et al., 2002), we used age-matched, cognitively normal controls as the comparison group $(n=24)$. For simplicity of presentation, the left and right ROIs for each brain area were combined into one bilateral ROI, but the same results were obtained with unilateral ROI data. If $A \beta$ deposition was driving the predominantly negative correlations discussed above for $\mathrm{AD}$ patients (i.e., increased $\mathrm{A} \beta$ causing reduced metabolism in $\mathrm{AD}$ ), then the increased load of $\mathrm{A} \beta$ observed in $\mathrm{AD}$ patients should be accompanied by reduced metabolism when compared to the amyloid-negative healthy controls. This should be particularly evident in the precuneus ROIs where the negative correlations between $\mathrm{PiB}$ retention and metabolism were the strongest (Fig. 1, matrices $I a, I V a$ ). Similar to many previously published reports (Minoshima, 2003; Silverman and Alavi, 2005; Herholz et al., 2007; Mosconi et al., 2007; Foster et al., 2008), increased $\mathrm{A} \beta$ deposition in the middle-precuneus of $\mathrm{AD}$ patients (Fig. $3 A)(p<0.0001)$ was accompanied by reduced metabolism (Fig. 3C) $(p<0.003)$. This was true whether the data were atrophy-corrected (as shown in Fig. 3) or not. Similar reductions were seen in other medial and lateral parietal regions (data not shown). The same relationship was not observed in the subgenual anterior cingulate, where increased $\mathrm{A} \beta$ deposition was not accompanied by a reduction in metabolism in $\mathrm{AD}$ (Figs. $3 B, D$ ).

Similarly, if $\mathrm{A} \beta$ deposition was driving the predominantly positive correlations discussed above for MCI patients (i.e., increased $\mathrm{A} \beta$ causing increased metabolism in $\mathrm{MCI}$ ), then the increased load of $\mathrm{A} \beta$ observed in MCI patients should be accompanied by increased metabolism when compared to the amyloid-negative healthy controls. This should be particularly evident in the anterior cingulate ROIs where the positive correlations between $\mathrm{PiB}$ retention and metabolism were the strongest (Fig. 1, matrices $I d-I V d$ ). However, increased $\mathrm{A} \beta$ deposition in the subgenual anterior cingulate of MCI patients (Fig. $3 B)(p<$ 0.0001 ) was not accompanied by increased metabolism (Fig. 3D) $(p=0.54)$. This was true of all subregions of the anterior cingulate, with or without atrophy correction. MCI patients showed a nonsignificant trend toward reduced metabolism in the middleprecuneus ROI (Fig. $3 C$ ) ( $p=0.06$ ). Figure 3, $C$ and $D$, also show that metabolism in the precuneus and anterior cingulate of the amyloid-positive controls was very similar to the amyloidnegative control group. That is, the increased $\mathrm{A} \beta$ deposition in these controls (Fig. $3 A, B)(p<0.0001)$ was not associated with a trend toward either higher or lower metabolism (Fig. $3 C, D$ ).

\section{Discussion}

Reductions of cerebral metabolism are well established in AD (Minoshima, 2003; Lopresti et al., 2005; Silverman and Alavi, 2005; Mosconi et al., 2007). The analysis of amyloid- $\beta$ deposition using PiB-PET is a more recent technology (Klunk et al., 2004; Ikonomovic et al., 2008), but the role of $\mathrm{A} \beta$ in $\mathrm{AD}$ pathogenesis has led to comparisons of $\mathrm{A} \beta$ deposition and metabolism in $\mathrm{AD}$. Some have reported negative correlations in parietal cortex in $\mathrm{AD}$ (Klunk et al., 2004; Engler et al., 2006), while others have not found this relationship (Kadir et al., 2008).

In this study, we assessed relationships between fibrillar $\mathrm{A} \beta$ pathology and metabolism across the spectrum of AD from normal controls with amyloid deposition to MCI subjects with amy- 
A

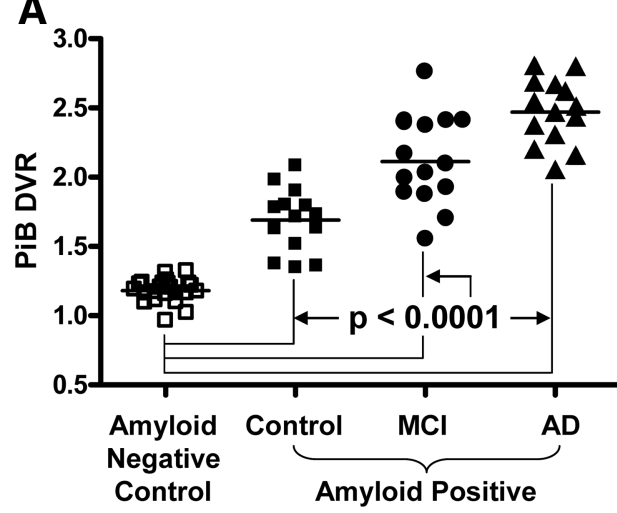

C
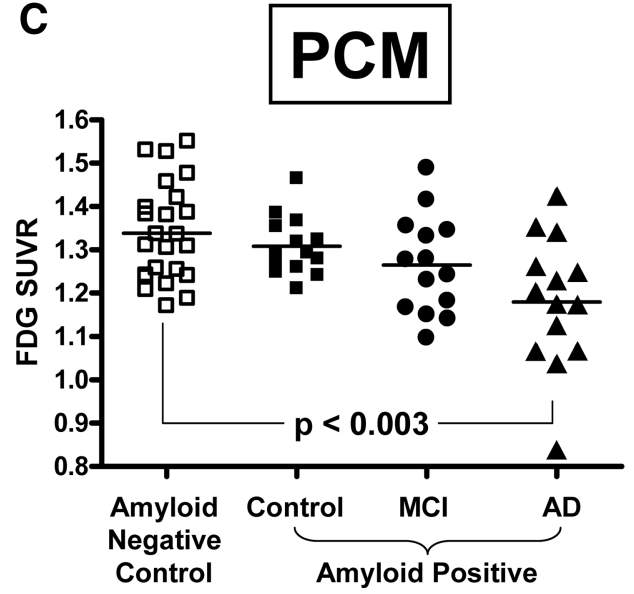

B
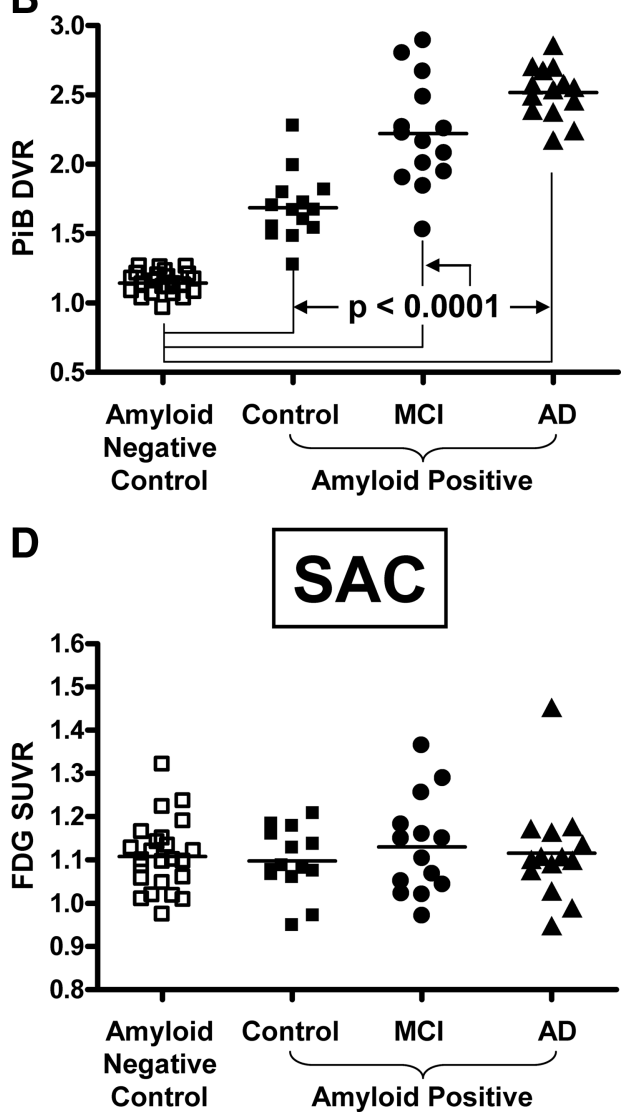

Figure 3. Group comparisons of PiB retention and glucose metabolism. $\boldsymbol{A}-\boldsymbol{D}$, PiB retention in bilateral, middle precuneus cortex ( $\boldsymbol{A}, \mathrm{PCM})$ or bilateral, subgenual anterior cingulate cortex ( $\boldsymbol{B}, \mathrm{SAC})$ and glucose metabolism in PCM (C) or SAC (D) in amyloid-negative controls (open squares), amyloid-positive controls (filled squares), MCI (filled circles), and AD (filled triangles). Significant differences of the amyloid-positive groups compared to the amyloid-negative controls are noted.

loid to AD patients. Both the PiB-PET and FDG-PET data were atrophy-corrected. For clinical purposes, a case can be made against atrophy correction of FDG-PET because both atrophy and hypometabolism increase sensitivity to detection of AD pathology. The focus of this study was not clinical sensitivity of FDG-PET, but was the correlation of $\mathrm{A} \beta$ deposition in a given volume of tissue to metabolism in that same tissue. By not atrophy correcting, we would include a confounding atrophy variable into these correlations. We limited inclusion of control subjects, MCI and AD patients to those who were amyloid-positive, as previously defined (Aizenstein et al., 2008). This was done to avoid invalid correlations across two distinct populations. While some of the individual correlations reported here are relatively weak, the majority survive the widely used method of false discovery rate control (Genovese et al., 2002) and support the general conclusions based on overall patterns of correlations between $\mathrm{PiB}$ retention and metabolism rather than individual correlations.

While voxel-based analyses supported the ROI-based analyses for the most part, certain outcomes remain unexplained. More striking findings were obtained in $\mathrm{AD}$ when $\mathrm{PiB}$ retention was assigned to the precuneus ROI and correlated to metabolism across all voxels than when metabolic data were assigned to the precuneus $\mathrm{ROI}$ and correlated to $\mathrm{PiB}$ retention across all voxels. The opposite was true in MCI. Differences between the ROIbased and voxel-based analyses may be partly because the precuneus ROIs used in the voxel-based analyses was a combination of right and left ROIs and combinations of several smaller, compo- nent ROIs. However, this finding may be a reflection of whether $\mathrm{A} \beta$ or metabolism is the driving force in $\mathrm{AD}$ and MCI.

We confirmed the local, negative correlation between PiB retention and metabolism in precuneus and parietal regions observed previously in $\mathrm{AD}$, consistent with a direct, local toxic effect of $A \beta$ on synaptic metabolism (Klunk et al., 2004; Engler et al., 2006). Metabolism in precuneus also was negatively correlated with $\mathrm{PiB}$ retention in frontal regions suggesting possible distant $\mathrm{A} \beta$ effects. However, it is important to note that $\mathrm{PiB}$ retention across many cortical areas are highly intercorrelated (Price et al., 2005). In the presence of local correlations, this covariance could generate apparent "distant" correlations even when none exist.

In contrast, there were no significant negative correlations between $\mathrm{PiB}$ retention and metabolism in MCI and extensive positive correlations in many brain areas. Metabolism in anterior cingulate, precuneus and parietal areas was positively correlated locally. Metabolism in anterior cingulate also was associated with $\mathrm{PiB}$ retention in more distant brain areas, but, the covariance of $\mathrm{PiB}$ retention across these regions must again be considered. In MCI, metabolism in precuneus, parietal, and occipital cortices was primarily correlated with $\mathrm{PiB}$ in posterior brain regions. These distant, positive correlations of $\mathrm{PiB}$ retention in the parietal/precuneus region with metabolism in occipital cortex, coupled to the lack of local correlations in occipital cortex, are the best evidence of distant effects of $A \beta$ deposition in this study.

The suggestion that reductions in parietal metabolism detected with FDG-PET in AD may be directly related to amyloid 
pathology (i.e., increased deposition of $\mathrm{A} \beta$ causes decreased metabolism) is not new (McGeer et al., 1986). The elevations in mean $\mathrm{PiB}$ retention and reductions in mean metabolic rate in precuneus and parietal cortex in $\mathrm{AD}$, coupled with the negative correlations between $\mathrm{PiB}$ retention and metabolism in these areas of AD patients, are consistent with this hypothesis. However, there is a relative disconnect between high levels of $\mathrm{A} \beta$ deposition in the frontal cortex without decreases in metabolism in this area. This has previously been reported by several groups and suggests that there may be region-specific mediators of the toxic effects of $\mathrm{A} \beta$ (Klunk et al., 2004; Edison et al., 2007; Li et al., 2008).

The positive correlations in MCI are more difficult to explain. One might hypothesize that the early deposition of $\mathrm{A} \beta$ in MCI results in higher metabolism as a compensatory or "distress" response. This hypothesis would be consistent with the increased hippocampal activation reported during functional MR imaging (fMRI) studies in MCI compared to either controls or AD (Dickerson et al., 2005). The findings that MCI patients with increased activations show greater cognitive decline over time (Miller et al., 2008) and increased hippocampal fMRI response in amyloid-positive subjects who had begun to show cognitive impairment $(\mathrm{CDR}=0.5)$, but not in those with stable, normal cognition $(\mathrm{CDR}=0)$, suggest this increased response may be "indicative of impending failure" (Sperling et al., 2009).

However, the hypothesis that increased $\mathrm{A} \beta$ deposition in MCI leads to increased metabolism would predict an elevation in metabolism in MCI that was not present in our data. More consistent with our data are hypotheses that: (1) higher basal metabolism retards the conversion from clinical MCI to AD (i.e., high metabolism is a form of brain reserve) or (2) higher basal metabolism accelerates $\mathrm{A} \beta$ deposition.

The "brain reserve" hypothesis might be conceptualized as shown in Figure $4 A$. In this model, cognition is a function of both $\mathrm{A} \beta$ load and cerebral metabolism. Reaching the MCI (gray) or $\mathrm{AD}$ (black) range of cognitive impairment requires more $\mathrm{A} \beta$ deposition at higher levels of metabolism. From Figure $4 B$, one can see how this might result in our findings of little correlation between amyloid and metabolism in controls, a strong positive correlation in MCI and a weaker negative correlation in AD.

The "acceleration" hypothesis suggests that once $\mathrm{A} \beta$ deposition is initiated by independent events, a milieu of higher metabolism hastens this deposition. This is not to suggest that increased metabolism is an early cause of $A \beta$ deposition. If this were the case, the amyloid-positive controls should have higher metabolism than the amyloid-negative controls, but this is not the case. It is possible that the FDG analysis technique used in this study is not sensitive enough to pick up subtle changes in amyloidpositive controls, or that $\mathrm{A} \beta$-induced synaptic alterations are present that are not amenable to detection by FDG-PET (e.g., increased inhibitory and decreased excitatory transmission).

It is interesting that there is considerable overlap between the regional distribution of amyloid deposition and the "default mode network" (Buckner et al., 2005), a group of brain areas that are more active during rest (Shulman et al., 1997; McKiernan et al., 2003). This spatial overlap has led to the hypothesis that there could be a relationship between brain activity patterns in early adulthood and later amyloid deposition (Buckner et al., 2005). This raises the possibility that when $\mathrm{A} \beta$ deposition starts, it becomes more pronounced in brain regions with high default mode activity. It has been shown in animals that $\mathrm{A} \beta$ levels are directly influenced by synaptic activity and are related to exocytosis of synaptic vesicles (Cirrito et al., 2005). Although much less direct, there is similar evidence in humans. Using intracerebral microdialysis in patients, positive correlations between $A \beta$ levels and neurological status have been reported (Brody et al., 2008).

This does not imply that increased brain activity in general increases the chances of developing AD. The opposite may be true as evidenced by the apparent protective effect of education and equivalent measures of cognitive/brain reserve (Stern, 2006). What these findings could mean is that brain activities that reduce default mode activity may be beneficial in both promoting cognitive/brain reserve (Fig. 4) and in reducing $\mathrm{A} \beta$ release and deposition in the vulnerable default mode network.

In summary, in $\mathrm{AD}$ we observed predominantly negative correlations between $\mathrm{PiB}$ retention and metabolism, along with decreased metabolism. This suggests that $\mathrm{A} \beta$ deposition could be a determinant of metabolism. That is, in the later stages of the pathological process, $A \beta$ oligomers and plaque accumulation may cause enough cellular destruction in the more vulnerable parietal and precuneus areas to result in proportional decreases in local and distant synaptic metabolism. In MCI, we observed exclusively positive correlations between $\mathrm{PiB}$ retention and metabolism, but no overall change in metabolism. This suggests that, in MCI, basal metabolism is more of a determinant of observed $\mathrm{A} \beta$ deposition than vice versa. Possible explanations include: (1) higher basal metabolism protects against clinical conversion from MCI to $\mathrm{AD}$ until later stages of $\mathrm{A} \beta$ deposition (i.e., high basal metabolism represents brain reserve); and (2) higher basal metabolism speeds $\mathrm{A} \beta$ deposition. Distinguishing between these possibilities would have important implications for the development of therapies aimed at stabilizing or augmenting basal cerebral metabolism.

\section{References}

Aizenstein HJ, Nebes RD, Saxton JA, Price JC, Mathis CA, Tsopelas ND, Ziolko SK, James JA, Snitz BE, Houck PR, Bi W, Cohen AD, Lopresti BJ, DeKosky ST, Halligan EM, Klunk WE (2008) Frequent amyloid deposition without significant cognitive impairment among the elderly. Arch Neurol 65:1509-1517. 
Ashburner J, Friston KJ (2005) Unified segmentation. Neuroimage 26: $839-851$.

Becker JT, Boller F, Saxton J, McGonigle-Gibson KL (1987) Normal rates of forgetting of verbal and non-verbal material in Alzheimer's disease. Cortex 23:59-72.

Bennett DA, Schneider JA, Wilson RS, Bienias JL, Arnold SE (2004) Neurofibrillary tangles mediate the association of amyloid load with clinical Alzheimer disease and level of cognitive function. Arch Neurol 61: $378-384$.

Bennett DA, Schneider JA, Arvanitakis Z, Kelly JF, Aggarwal NT, Shah RC, Wilson RS (2006) Neuropathology of older persons without cognitive impairment from two community-based studies. Neurology 66:18371844.

Benton AL (1968) Differential behavioral effects in frontal lobe disease. Neuropsychologia 6:53-60.

Borkowski JG, Benton AL, Spreen O (1967) Word fluency and brain damage. Neuropsychologia 5:135-140.

Brody DL, Magnoni S, Schwetye KE, Spinner ML, Esparza TJ, Stocchetti N, Zipfel GJ, Holtzman DM (2008) Amyloid-beta dynamics correlate with neurological status in the injured human brain. Science 321:1221-1224.

Buckner RL, Snyder AZ, Shannon BJ, LaRossa G, Sachs R, Fotenos AF, Sheline YI, Klunk WE, Mathis CA, Morris JC, Mintun MA (2005) Molecular, structural, and functional characterization of Alzheimer's disease: evidence for a relationship between default activity, amyloid, and memory. J Neurosci 25:7709-7717.

Cheng C, Pounds SB, Boyett JM, Pei D, Kuo ML, Roussel MF (2004) Statistical significance threshold criteria for analysis of microarray gene expression data. Stat Appl Genet Mol Biol 3:Article36.

Cirrito JR, Yamada KA, Finn MB, Sloviter RS, Bales KR, May PC, Schoepp DD, Paul SM, Mennerick S, Holtzman DM (2005) Synaptic activity regulates interstitial fluid amyloid-beta levels in vivo. Neuron 48:913-922.

Dickerson BC, Salat DH, Greve DN, Chua EF, Rand-Giovannetti E, Rentz DM, Bertram L, Mullin K, Tanzi RE, Blacker D, Albert MS, Sperling RA (2005) Increased hippocampal activation in mild cognitive impairment compared to normal aging and AD. Neurology 65:404-411.

Edison P, Archer HA, Hinz R, Hammers A, Pavese N, Tai YF, Hotton G, Cutler D, Fox N, Kennedy A, Rossor M, Brooks DJ (2007) Amyloid, hypometabolism, and cognition in Alzheimer disease. An [11C]PIB and [18F]FDG PET study. Neurology 68:501-508.

Engler H, Forsberg A, Almkvist O, Blomquist G, Larsson E, Savitcheva I, Wall A, Ringheim A, Långström B, Nordberg A (2006) Two-year follow-up of amyloid deposition in patients with Alzheimer's disease. Brain 129:2856-2866.

Folstein MF, Folstein SE, McHugh PR (1975) "Mini-mental state". A practical method for grading the cognitive state of patients for the clinician. J Psychiatr Res 12:189-198.

Forsberg A, Engler H, Almkvist O, Blomquist G, Hagman G, Wall A, Ringheim A, Långström B, Nordberg A (2008) PET imaging of amyloid deposition in patients with mild cognitive impairment. Neurobiol Aging 29:1456-1465.

Foster NL, Heidebrink JL, Clark CM, Jagust WJ, Arnold SE, Barbas NR, DeCarli CS, Turner RS, Koeppe RA, Higdon R, Minoshima S (2007) FDG-PET improves accuracy in distinguishing frontotemporal dementia and Alzheimer's disease. Brain 130:2616-2635.

Foster NL, Wang AY, Tasdizen T, Fletcher PT, Hoffman JM, Koeppe RA (2008) Realizing the potential of positron emission tomography with $18 \mathrm{~F}-$ fluorodeoxyglucose to improve the treatment of Alzheimer's disease. Alzheimers Dement 4:S29-36.

Friedland RP, Budinger TF, Ganz E, Yano Y, Mathis CA, Koss B, Ober BA, Huesman RH, Derenzo SE (1983) Regional cerebral metabolic alterations in dementia of the Alzheimer type: positron emission tomography with [18F] fluorodeoxyglucose. J Comput Assist Tomogr 7:590-598.

Gauthier S, Reisberg B, Zaudig M, Petersen RC, Ritchie K, Broich K, Belleville S, Brodaty H, Bennett D, Chertkow H, Cummings JL, de Leon M, Feldman H, Ganguli M, Hampel H, Scheltens P, Tierney MC, Whitehouse P, Winblad B (2006) Mild cognitive impairment. Lancet 367:1262-1270.

Genovese CR, Lazar NA, Nichols T (2002) Thresholding of statistical maps in functional neuroimaging using the false discovery rate. Neuroimage 15:870-878.

Hamacher K, Coenen HH, Stöcklin G (1986) Efficient stereospecific synthesis of no-carrier-added 2-[18F]-fluoro-2-deoxy-D-glucose using aminopolyether supported nucleophilic substitution. J Nucl Med 27:235-238.
Herholz K, Salmon E, Perani D, Baron JC, Holthoff V, Frölich L, Schönknecht P, Ito K, Mielke R, Kalbe E, Zündorf G, Delbeuck X, Pelati O, Anchisi D, Fazio F, Kerrouche N, Desgranges B, Eustache F, Beuthien-Baumann B, Menzel C, et al. (2002) Discrimination between Alzheimer dementia and controls by automated analysis of multicenter FDG PET. Neuroimage 17:302-316.

Herholz K, Carter SF, Jones M (2007) Positron emission tomography imaging in dementia. Br J Radiol 80:S160-S167.

Ikonomovic MD, Klunk WE, Abrahamson EE, Mathis CA, Price JC, Tsopelas ND, Lopresti BJ, Ziolko S, Bi W, Paljug WR, Debnath ML, Hope CE, Isanski BA, Hamilton RL, DeKosky ST (2008) Post-mortem correlates of in vivo PiB-PET amyloid imaging in a typical case of Alzheimer's disease. Brain 131:1630-1645.

Jagust W, Reed B, Mungas D, Ellis W, Decarli C (2007) What does fluorodeoxyglucose PET imaging add to a clinical diagnosis of dementia? Neurology 69:871-877.

Kadir A, Andreasen N, Almkvist O, Wall A, Forsberg A, Engler H, Hagman G, Lärksäter M, Winblad B, Zetterberg H, Blennow K, Långström B, Nordberg A (2008) Effect of phenserine treatment on brain functional activity and amyloid in Alzheimer's disease. Ann Neurol 63:621-631.

Klunk WE, Engler H, Nordberg A, Wang Y, Blomqvist G, Holt DP, Bergström M, Savitcheva I, Huang GF, Estrada S, Ausén B, Debnath ML, Barletta J, Price JC, Sandell J, Lopresti BJ, Wall A, Koivisto P, Antoni G, Mathis CA, et al. (2004) Imaging brain amyloid in Alzheimer's disease with Pittsburgh Compound-B. Ann Neurol 55:306-319.

Klunk WE, Price JC, Mathis CA, Tsopelas ND, Lopresti BJ, Ziolko SK, Bi W, Hoge JA, Cohen AD, Ikonomovic MD, Saxton JA, Snitz BE, Pollen DA, Moonis M, Lippa CF, Swearer JM, Johnson KA, Rentz DM, Fischman AJ, Aizenstein HJ, et al. (2007) Amyloid deposition begins in the striatum of presenilin-1 mutation carriers from two unrelated pedigrees. J Neurosci $27: 6174-6184$.

Li Y, Rinne JO, Mosconi L, Pirraglia E, Rusinek H, DeSanti S, Kemppainen N, Någren K, Kim BC, Tsui W, de Leon MJ (2008) Regional analysis of FDG and PIB-PET images in normal aging, mild cognitive impairment, and Alzheimer's disease. Eur J Nucl Med Mol Imaging 35:2169-2181.

Lopez OL, Becker JT, Klunk W, Saxton J, Hamilton RL, Kaufer DI, Sweet RA, Cidis Meltzer C, Wisniewski S, Kamboh MI, DeKosky ST (2000) Research evaluation and diagnosis of probable Alzheimer's disease over the last two decades: I. Neurology 55:1854-1862.

Lopresti BJ, Klunk WE, Mathis CA, Hoge JA, Ziolko SK, Lu X, Meltzer CC, Schimmel K, Tsopelas ND, DeKosky ST, Price JC (2005) Simplified quantification of Pittsburgh Compound B amyloid imaging PET studies: a comparative analysis. J Nucl Med 46:1959-1972.

McGeer PL, Kamo H, Harrop R, McGeer EG, Martin WR, Pate BD, Li DK (1986) Comparison of PET, MRI, and CT with pathology in a proven case of Alzheimer's disease. Neurology 36:1569-1574.

McKiernan KA, Kaufman JN, Kucera-Thompson J, Binder JR (2003) A parametric manipulation of factors affecting task-induced deactivation in functional neuroimaging. J Cogn Neurosci 15:394-408.

Mega MS, Chu T, Mazziotta JC, Trivedi KH, Thompson PM, Shah A, Cole G, Frautschy SA, Toga AW (1999) Mapping biochemistry to metabolism: FDG-PET and amyloid burden in Alzheimer's disease. Neuroreport 10:2911-2917.

Meltzer CC, Kinahan PE, Greer PJ, Nichols TE, Comtat C, Cantwell MN, Lin MP, Price JC (1999) Comparative evaluation of MR-based partial volume correction schemes for PET. J Nucl Med 40:2053-2065.

Miller SL, Fenstermacher E, Bates J, Blacker D, Sperling RA, Dickerson BC (2008) Hippocampal activation in adults with mild cognitive impairment predicts subsequent cognitive decline. J Neurol Neurosurg Psychiatry 79:630-635.

Minoshima S (2003) Imaging Alzheimer's disease: clinical applications. Neuroimaging Clin N Am 13:769-780.

Minoshima S, Frey KA, Foster NL, Kuhl DE (1995) Preserved pontine glucose metabolism in Alzheimer disease: a reference region for functional brain image (PET) analysis. J Comput Assist Tomogr 19:541-547.

Mintun MA, Larossa GN, Sheline YI, Dence CS, Lee SY, Mach RH, Klunk WE, Mathis CA, DeKosky ST, Morris JC (2006) $\left[{ }^{11} \mathrm{C}\right] \mathrm{PIB}$ in a nondemented population: potential antecedent marker of Alzheimer disease. Neurology 67:446-452.

Morris JC (1993) The Clinical Dementia Rating (CDR): current version and scoring rules. Neurology 43:2412-2414.

Mosconi L, Brys M, Glodzik-Sobanska L, De Santi S, Rusinek H, de Leon MJ 
(2007) Early detection of Alzheimer's disease using neuroimaging. Exp Gerontol 42:129-138.

Petersen RC (2004) Mild cognitive impairment as a diagnostic entity. J Intern Med 256:183-194.

Petersen RC, Parisi JE, Dickson DW, Johnson KA, Knopman DS, Boeve BF, Jicha GA, Ivnik RJ, Smith GE, Tangalos EG, Braak H, Kokmen E (2006) Neuropathologic features of amnestic mild cognitive impairment. Arch Neurol 63:665-672.

Price JC, Klunk WE, Lopresti BJ, Lu X, Hoge JA, Ziolko SK, Holt DP, Meltzer CC, DeKosky ST, Mathis CA (2005) Kinetic modeling of amyloid binding in humans using PET imaging and Pittsburgh Compound-B. J Cereb Blood Flow Metab 25:1528-1547.

Price JL, Morris JC (1999) Tangles and plaques in nondemented aging and "preclinical" Alzheimer's disease. Ann Neurol 45:358-368.

Prohovnik I, Perl DP, Davis KL, Libow L, Lesser G, Haroutunian V (2006) Dissociation of neuropathology from severity of dementia in late-onset Alzheimer disease. Neurology 66:49-55.

Raji CA, Becker JT, Tsopelas ND, Price JC, Mathis CA, Saxton JA, Lopresti BJ, Hoge JA, Ziolko SK, DeKosky ST, Klunk WE (2008) Characterizing regional correlation, laterality and symmetry of amyloid deposition in mild cognitive impairment and Alzheimer's disease with Pittsburgh Compound B. J Neurosci Methods 172:277-282.

Reiman EM, Caselli RJ, Yun LS, Chen K, Bandy D, Minoshima S, Thibodeau SN, Osborne D (1996) Preclinical evidence of Alzheimer's disease in persons homozygous for the epsilon 4 allele for apolipoprotein E. N Engl J Med 334:752-758.

Reitan RM (1958) Validity of the Trail-making Tests as an indication of organic brain damage. Percept Mot Skills 8:271-276.

Saxton J, Ratcliff G, Newman A, Belle S, Fried L, Yee J, Kuller L (2000) Cognitive test performance and presence of subclinical cardiovascular disease in the cardiovascular health study. Neuroepidemiology 19: 312-319.

Schneider JA, Arvanitakis Z, Bang W, Bennett DA (2007) Mixed brain pathologies account for most dementia cases in community-dwelling older persons. Neurology 69:2197-2204.

Shankar GM, Li S, Mehta TH, Garcia-Munoz A, Shepardson NE, Smith I, Brett FM, Farrell MA, Rowan MJ, Lemere CA, Regan CM, Walsh DM, Sabatini BL, Selkoe DJ (2008) Amyloid-beta protein dimers isolated directly from Alzheimer's brains impair synaptic plasticity and memory. Nat Med 14:837-842.
Shulman GL, Fiez JA, Corbetta M, Buckner RL, Miezin FM, Raichle ME, Petersen SE (1997) Common blood flow changes across visual tasks: II. Decreases in cerebral cortex. J Cogn Neurosci 9:648-663.

Silverman DH, Alavi A (2005) PET imaging in the assessment of normal and impaired cognitive function. Radiol Clin North Am 43:67-77, x.

Small GW, Ercoli LM, Silverman DH, Huang SC, Komo S, Bookheimer SY, Lavretsky H, Miller K, Siddarth P, Rasgon NL, Mazziotta JC, Saxena S, Wu HM, Mega MS, Cummings JL, Saunders AM, Pericak-Vance MA, Roses AD, Barrio JR, Phelps ME (2000) Cerebral metabolic and cognitive decline in persons at genetic risk for Alzheimer's disease. Proc Natl Acad Sci U S A 97:6037-6042.

Sperling RA, Laviolette PS, O'Keefe K, O’Brien J, Rentz DM, Pihlajamaki M, Marshall G, Hyman BT, Selkoe DJ, Hedden T, Buckner RL, Becker JA, Johnson KA (2009) Amyloid deposition is associated with impaired default network function in older persons without dementia. Neuron 63:178-188.

Stern Y (2006) Cognitive reserve and Alzheimer disease. Alzheimer Dis Assoc Disord 20:S69-74.

Stern Y, Zarahn E, Hilton HJ, Flynn J, DeLaPaz R, Rakitin B (2003) Exploring the neural basis of cognitive reserve. J Clin Exp Neuropsychol 25:691-701.

Wechsler D (1997) Wechsler adult intelligence scale, Ed 3. New York: The Psychological Corporation.

Welsh KA, Butters N, Mohs RC, Beekly D, Edland S, Fillenbaum G, Heyman A (1994) The Consortium to Establish a Registry for Alzheimer's Disease (CERAD). Part V. A normative study of the neuropsychological battery. Neurology 44:609-614.

Wilson AA, Garcia A, Chestakova A, Kung HF, Houle S (2004) A rapid one-step radiosynthesis of the beta-amyloid imaging radiotracer N-methyl-[C-11]2(4'-methylaminophenyl)-6-hydroxybenzothiazole ([C-11]-6-OH-BTA-1). J Label Compd Radiopharm 47:679-682.

Wolf DS, Gearing M, Snowdon DA, Mori H, Markesbery WR, Mirra SS (1999) Progression of regional neuropathology in Alzheimer disease and normal elderly: findings from the Nun study. Alzheimer Dis Assoc Disord 13:226-231.

Ziolko SK, Weissfeld LA, Klunk WE, Mathis CA, Hoge JA, Lopresti BJ, DeKosky ST, Price JC (2006) Evaluation of voxel-based methods for the statistical analysis of PIB PET amyloid imaging studies in Alzheimer's disease. Neuroimage 33:94-102. 